\title{
Friendship Motivation, Aggression, and Self-Esteem in Japanese Undergraduate Students
}

\author{
Ryo Okada \\ Faculty of Education, Kagawa University, Kagawa, Japan \\ Email: ryooo@ed.kagawa-u.ac.jp
}

Received October $13^{\text {th }}, 2011$; revised November $14^{\text {th }}, 2011$; accepted December $17^{\text {th }}, 2011$

\begin{abstract}
The purpose of this study was to examine the relationship among self-determined friendship motivation (motivation for friendship formation), aggression, and self-esteem in a sample of 262 Japanese university students. The hypothetical model posited that self-determined friendship motivation predicted lower levels of aggression, which, in turn, predicted lower levels of self-esteem. The results showed that self-determined friendship motivation predicted lower levels of anger, hostility, and physical aggression and that hostility and anger predicted lower levels of self-esteem. Verbal aggression was found to be positively associated with self-determined friendship motivation and self-esteem. The different relationships between self-determined friendship motivation and each facet of aggression are discussed.
\end{abstract}

Keywords: Friendship Motivation; Aggression; Self-Esteem; Self-Determination Theory

\section{Introduction}

During adolescence, friendship plays an important role in one's life. Hartup and Stevens (1997) stated that friends are cognitive and affective resources that foster self-esteem and a sense of well-being. A number of empirical studies have revealed that friendship influences individuals' well-being and psychological adjustment (Lucas \& Dyrenforth, 2006).

Researchers have recently examined the relationship between friendship formation and motivation. Motivation for friendship formation (i.e., friendship motivation) has been conceptualized in various motivational theories, for example, achievement goal theory (Elliot, Gable, \& Mapes, 2006; Ryan \& Shim, 2006), self-efficacy theory (Matsushima \& Shiomi, 2003; Patrick, Ryan, \& Kaplan, 2007), and social goal theory (Jarvinen \& Nicholls, 1996). Another theory, the self-determination theory (Deci \& Ryan, 2000) has proposed a comprehensive framework for friendship motivation. It conceptualizes several types of motivation in terms of the level of self-determination - external regulation, introjected regulation, identified regulation, and intrinsic motivation. External regulation refers to motivation by contingencies such as external rewards or punishment and motivation by others' initiative. Sometimes, individuals continue to talk to a certain friend merely because the friend talks to them. This is an example of external regulation. Introjected regulation refers to motivation stemming from feelings of anxiety or shame. The purpose of behaviors motivated by introjected regulation is to maintain one's self-esteem. Individuals guided by introjected regulation believe that they "should" form and maintain friendships with others. Identified regulation refers to motivation based on perceptions of the value and importance of the activity. For individuals motivated by identified regulation, friendships are very important interpersonal relationships. However, they also see their friendships as means to achieve other ends such as personal happiness and growth. Intrinsic motivation refers to spontaneous motivation characterized by fun and inherent enjoyment. In this motivational state, the friendship is a purpose. Enjoying talking to and being in the company of friends is an example of intrinsic motivation. Empirical studies have examined the role of motivation in adolescents' friendship (Boiché \& Sarrazin, 2007; Hawley, Little, \& Pasupathi, 2002; Senécal, Julien, \& Guay, 2003).

The different types of motivation can be placed along a self-determination continuum, with external regulation at the lower end of the continuum and intrinsic motivation at the higher end. The self-determination level of an individual's motivation is characterized by the magnitude of these four types of motivation (Deci \& Ryan, 2000). In empirical studies, Relative Autonomy Index (RAI) was used to assess the level of selfdetermination of the individuals' motivation (Grolnick \& Ryan, 1987; Levesque, Zuehlke, Stanek, \& Ryan, 2004). The RAI is formed by weighting each subscale in accord with its underlying scores on the self-determination continuum in the following formula: $\mathrm{RAI}=(-2 \times$ external regulation $)+(-1 \times$ introjected regulation $)+(1 \times$ identified regulation $)+(2 \times$ intrinsic motivation). Higher scores of RAI represent higher levels of self-determined motivation.

Previous studies have verified the importance of self-determined friendship motivation. Okada (2005) developed a scale to measure friendship motivation and found that self-determined friendship motivation predicted prosocial behavior. Richard and Schneider (2005) revealed that children with higher levels of self-determined friendship motivation had more relationship-maintaining goals and were liked by their peers. Self-determined friendship motivation was also related to selfdisclosure (Okada, 2006), academic help-seeking (Okada, 2007), social competence (Soenens \& Vansteenkiste, 2005), and experience of positive life events (Shahar, Henrich, Blatt, \& Ryan, 2003). These findings suggest that self-determined friendship motivation promotes adaptive behaviors and positive interactions with friends.

Although the relationship between self-determined friendship motivation and adaptive behaviors has been verified in some 
studies, few studies have examined the relationship between self-determined friendship motivation and maladaptive behaviors during adolescence. On the basis of some relevant studies, it was predicted that self-determined friendship motivation was negatively associated with maladaptive behaviors. Knee, Lonsbary, Canevello, and Patrick (2005), for example, observed couples discussing their relationship conflicts and examined the relationship between their motivations and behaviors. The results showed that individuals with higher levels of self-determined motivation for their relationships (i.e., couple motivation) displayed less defensive behaviors such as blame and downplaying problems. In addition, Richard and Schneider (2005) found that external regulation for friendship, which represents lower levels of self-determined friendship motivation, was positively related to control and revenge goals in preadolescents and early adolescents. On the basis of these findings, it was hypothesized that self-determined friendship motivation predicted less maladaptive behaviors.

In examining the relationship between self-determined friendship motivation and maladaptive behaviors, this study focused on aggression. Aggressive or hostile individuals tend to receive less social support (Barefoot, Dahlstrom, \& Williams, 1983), and aggression and hostility can lead to poor physical health (Miller, Smith, Turner, Guijarro, \& Hallet, 1996). Therefore, determining the factors that predict aggression will be useful viewpoint for researchers and practitioners in this field. Buss and Perry (1992) developed the Buss-Perry Aggression Questionnaire and found four facets of aggression-physical aggression, verbal aggression, anger, and hostility. Later studies revealed that these four facets of aggression were related to depression (Gerevich, Bácskai, \& Czobor, 2007), negative interpersonal relationships (Harris, 1997), anger to mistreatment (Felsten \& Hill, 1999), aggressive responses to provocation (O'Connor, Archer, \& Wu, 2001), and daily negative affect (Harmon-Jones, 2003). People with higher levels of self-determined friendship motivation find fun and personal value in their friendships and therefore, rarely act aggressively. On the other hand, people with lower levels of self-determined friendship motivation feel obligated and anxious about relationships with their friends, so they are inclined to feel hostile and act aggressively. Therefore, it was hypothesized that self-determined friendship motivation predicted lower levels of the four facets of aggression.

In previous studies (Deci, Ryan, Gagné, Leone, Usunov, \& Kornazheva, 2001; Levesque, et al., 2004), self-esteem has been examined as an outcome variable predicted by self-determined motivation. Given that self-determined friendship motivation would be positively related to self-esteem, it was predicted that aggression would mediate the relationship. According to sociometer theory (Leary, Tambor, Terdal, \& Downs, 1995), self-esteem is part of a psychological system that monitors acceptance and rejection by others. People can gauge whether they are accepted or rejected by others from changes in their self-esteem. In support of this theory, the experimental manipulations that convey rejection reduce participants' self-esteem, whereas those that convey acceptance enhance their selfesteem (Leary \& Baumeister, 2000). Because aggression is likely to lead to rejection by friends, aggressive individuals would report lower levels of self-esteem.

In summary, the purpose of this study was to examine a model in which self-determined friendship motivation would predict lower levels of aggression, which, in turn, would predict lower levels of self-esteem. The examination of the model would reveal the role of motivation in adolescents' friendship from the side of maladaptive behaviors.

\section{Method}

\section{Participants and Procedure}

The participants comprised 262 Japanese university students (101 men and 161 women) with a mean age of 20.10 years (SD $=1.05$ ). All participants were volunteers and were informed at the start that the outcome and participation would not affect their course grades. After the orientation, the participants filled a questionnaire.

\section{Measures}

Self-determined friendship motivation was measured by the Friendship Motivation Scale developed by Okada (2005). This scale assesses the reasons for forming friendships and interacting with friends. There are four subscales of four items each: external regulation (e.g., "Because my friends would get mad at me if I'm not with them"), introjected regulation (e.g., "Because I would feel anxious if I didn't have any friends"), identified regulation (e.g., "Because I value getting to know my friends better"), and intrinsic motivation (e.g., "Because I'm glad to be intimate with my friends"). The instruction was "Why do you have close relationships with your friends or spend time together with your friends?" Participants were also instructed that "friends" does not refer to specific friends but friends in general. Participants were asked to rate each item on a 5-point Likert scale ranging from 1 (not true) to 5 (true). The reliabilities for each subscale were verified in a sample of Japanese university students (Cronbach alphas ranged from .61 to .86 , and test-retest coefficients during the three weeks ranged from .68 to .80 ; Okada, 2005). In the present study, the alphas for the subscales were .45 for external regulation, .74 for introjected regulation, .80 for identified regulation, and .88 for intrinsic motivation. Although the value of external regulation was relatively small, omission of an item slightly improved the value $(\alpha=.55)$. The descriptive score of external regulation was the average of the three items, and the descriptive scores of the other three subscales were calculated by averaging each of the four item scores. For the purpose of this study, the RAI was calculated same as previous studies (Grolnick \& Ryan, 1987; Levesque, et al., 2004; Losier \& Vallerand, 1994). The RAI is formed by weighting each subscale in accord with its underlying scores on the self-determination continuum in the following formula: $\mathrm{RAI}=(-2 \times$ external regulation $)+(-1 \times$ introjected regulation $)+(1 \times$ identified regulation $)+(2 \times$ intrinsic motivetion). In the subsequent analyses, the RAI score was used as an index of self-determined friendship motivation.

The Japanese version of the Buss and Perry Aggression Questionnaire (Buss \& Perry, 1992) developed by Ando, Soga, Yamasaki, Shimai, Shimada, Utsuki, Oashi, and Sakai (1999) was used to assess aggression. This scale consists of four subscales of physical aggression (5 items; e.g., "If somebody hits me, I hit back"), verbal aggression (6 items; e.g., "I tell my friends openly when I disagree with them"), anger (5 items; e.g., "I have trouble controlling my temper"), and hostility (6 items; e.g., "I sometimes feel that people are laughing at me behind my back"). Participants were asked to rate each item on a 5point Likert scale ranging from 1 (not true) to 5 (true). The 
reliabilities for each subscale were verified in a sample of Japanese university students (Cronbach alphas ranged from .70 to .78 , and test-retest coefficients during the three weeks ranged from .70 to .80; Ando, et al., 1999). In the present study, the alphas for the subscales were .78 for physical aggression, .75 for verbal aggression, .76 for anger, and .74 for hostility. The descriptive scores of the four subscales were calculated by averaging the item scores.

Self-esteem was measured with the Japanese version of Rosenberg's Self-Esteem Scale (10 items) developed by Yamamoto, Matsui, and Yamanari (1982). Participants were asked to rate each item on a 5-point Likert scale ranging from 1 (not true) to 5 (true). The Cronbach alpha was .84 in the present study. The descriptive score was calculated by averaging ten item scores.

\section{Results}

\section{Descriptive Statistics and Correlations among Variables}

Descriptive statistics and Pearson correlations among variables are presented in Table 1. Consistent with predictions, RAI was negatively related to anger $(r=-.24, p<.001)$ and hostility $(r=-.29, p<.001)$. The relation between RAI and physical aggression was marginally significant $(r=-.10, p<.10)$. Unexpectedly, RAI was positively associated with verbal aggression $(r=.18, p<.01)$. RAI was also positively related to self-esteem $(r=.25, p<.001)$. Anger and hostility were negatively related to self-esteem $(r \mathrm{~s}=-.18$ and $-.38, p \mathrm{~s}<.01$, respectively). Against predictions, verbal aggression was positively associated with self-esteem $(r=.34, p<.001)$. The relation between physical aggression and self-esteem was nearly zero $(r=-.00$, n.s. $)$.

\section{Examination of the Hypothetical Model}

It was hypothesized that self-determined friendship motivation would predict lower levels of aggression, which, in turn, would predict higher levels of self-esteem. The hypothetical model was constructed in the following manner. Paths from RAI to four aggression scores and paths from four aggression scores to self-esteem were postulated. Covariances among four aggression scores were also included.

The model was tested using structural equation modeling with AMOS 17.0. The model fit was assessed by the following statistics (Byrne, 2001): the chi-square value (nonsignificant values represent an acceptable fit), the Goodness of Fit Index
(GFI; values above .90 represent an acceptable fit), Adjusted Goodness of Fit Index (AGFI; values above .90 represent an acceptable fit), Comparative Fit Index (CFI; values above .90 represent an acceptable fit), and the Root Mean Square Error of Approximation (RMSEA; values below .08 represent an acceptable fit).

The analysis showed that the hypothetical model adequately fit the data, $\chi^{2}(1)=1.95$, n.s., GFI $=1.00, \mathrm{AGFI}=.95, \mathrm{CFI}=$ 1.00 , and RMSEA $=.06$. The path from physical aggression to self-esteem $(\beta=.03)$ and the covariance between verbal aggression and hostility $(r=.03)$ were nonsignificant; these parameters were therefore fixed at zero in the final model. Because the path from RAI to physical aggression $(\beta=-.10, p$ $<.10)$ and the path from anger to self-esteem $(\beta=-.11, p<.10)$ were marginally significant, these paths were freely estimated again. The final model is depicted in Figure 1. The analysis showed that the model adequately fit the data, $\chi^{2}(3)=2.32$, n.s., $\mathrm{GFI}=1.00$, AGFI $=.98, \mathrm{CFI}=1.00, \mathrm{RMSEA}=.00$, and the change of chi square values was also nonsignificant $\left(\Delta \chi^{2}(2)=\right.$ 0.37 , n.s.). The RAI predicted higher levels of verbal aggression $(\beta=.18, p<.01)$ and lower levels of anger and hostility $(\beta \mathrm{s}=-.24$ and $-.29, p \mathrm{~s}<.001$, respectively). The path from RAI to physical aggression was negative at a marginally significant level $(\beta=-.10, p<.10)$. Verbal aggression predicted higher levels of self-esteem $(\beta=.34, p<.001)$ and hostility predicted lower levels of self-esteem $(\beta=-.32, p<.001)$. Anger predicted lower levels of self-esteem at a marginally significant level $(\beta=-.11, p<.10)$.

\section{Discussion}

The purpose of this study was to examine a model in which self-determined friendship motivation would predict lower levels of aggression, which, in turn, would predict lower levels of self-esteem. Consistent with the hypothetical model, path analyses showed that self-determined friendship motivation predicted lower levels of anger, hostility, and physical aggression, and hostility and anger predicted lower levels of selfesteem. People with higher levels of self-determined friendship motivation are likely to feel less anger and hostility and to act less aggressively in their relationships with friends, because they are motivated by their interest in friends or the importance of friendship. People who display less hostility and anger toward friends are likely to be more accepted, and those who interact with others in a hostile and angry manner tend to be avoided and rejected. Hostility and anger lead to rejection by

Table 1.

Pearson correlations among variables, means, and standard deviations.

\begin{tabular}{|c|c|c|c|c|c|c|c|}
\hline & 1 & 2 & 3 & 4 & 5 & Mean & $S D$ \\
\hline 1. RAI & & & & & & 5.87 & 2.77 \\
\hline 2. Physical aggression & $-.10^{\dagger}$ & & & & & 2.70 & 0.81 \\
\hline 3. Verbal aggression & $.18^{* *}$ & $.33^{* * *}$ & & & & 2.90 & 0.77 \\
\hline 4. Anger & $-.24^{* * *}$ & $.42^{* * *}$ & $.18^{* * *}$ & & & 2.84 & 0.84 \\
\hline 5. Hostility & $-.29^{* * *}$ & $.29^{* * *}$ & -.03 & $.43^{* * *}$ & & 3.03 & 0.72 \\
\hline 6. Self-esteem & $.25^{* * *}$ & -.00 & $.34^{* * *}$ & $-.18^{* *}$ & $-.38^{* * *}$ & 3.13 & 0.68 \\
\hline
\end{tabular}




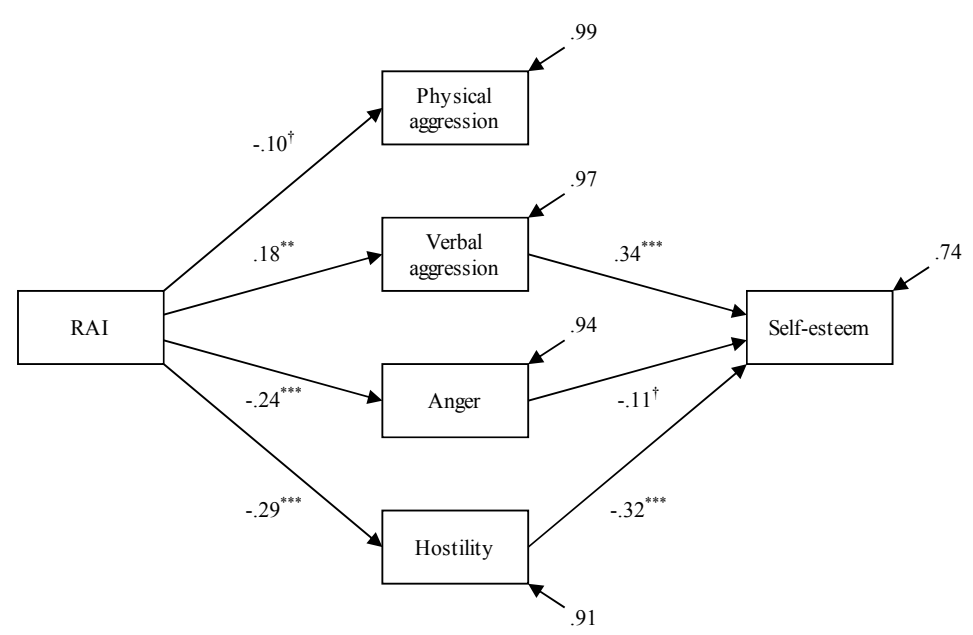

Figure 1.

A hypothetical model of the relationship among RAI, aggression subscales, and selfesteem. The covariances among the aggression subscales are omitted in this figure. ${ }^{\dagger} p$ $<.10,{ }^{* *} p<.01,{ }^{* * *} p<.001$.

others and could therefore decrease self-esteem, as suggested in sociometer theory (Leary \& Baumeister, 2000; Leary, et al., 1995).

It was surprising to find that self-determined friendship motivation predicted higher levels of verbal aggression, which, in turn, predicted higher levels of self-esteem. This is an unexpected finding. A plausible explanation is that verbal aggression helps maintain relationships with friends. The content of the items that tap verbal aggression ("I tell my friends openly when I disagree with them," "When people annoy me, I may tell them what I think of them") seems to be similar to assertion, which is a component of interpersonal competence. Buhrmester, Furman, Wittenberg, and Reis (1988) suggested that asserting displeasure with others was an aspect of interpersonal competence and was positively related to social self-esteem. Soenens and Vansteenkiste (2005) found that self-determined friendship motivation predicted higher levels of social competence, which was a similar construct to interpersonal competence. It can be that people with higher levels of self-determined friendship motivation maintain positive relationships with friends through asserting their own opinion honestly, consequently maintaining high self-esteem.

Physical aggression was not found to be significantly related to self-esteem. Generally, aggression is likely to lead to rejection by others, and rejection will decrease self-esteem. On the other hand, aggressive behavior can help in restoring self-esteem that has been lowered by negative evaluation and feedback (Baumeister, Smart, \& Boden, 1996). If the attempt to restore self-esteem succeeds, aggression can be associated with higher levels of self-esteem. The nonsignificant relationship between physical aggression and self-esteem in this study may partly reflect the need for aggressive responses as a means to restore self-esteem.

The main contribution of this study was to reveal that friendship motivation could influence self-esteem through lower levels of maladaptive behaviors. Previous studies have mainly examined the relationship between self-determined friendship motivation and adaptive behaviors (Okada, 2007; Richard \& Schneider, 2005; Soenens \& Vansteenkiste, 2005). The present study focused on aggression as a maladaptive behavior and revealed the relationship between self-determined friendship motivation and aggression. It was suggested that self-determined friendship motivation not only promotes adaptive behaviors but also suppresses aggressive and hostile behaviors.

It is important to note that some of the relationships found in this study were relatively weak. For example, the path coefficient from RAI to physical aggression was -.10 in the path analysis, although the value was marginally significant. This may partly be because general aggression in daily life was examined in this study. Another line of research has examined aggressive responses in specific situations manipulated experimentally such as provocation, ego-threat, and social exclusion (Baumeister, et al., 1996; O'Connor, et al., 2001; Twenge, 2006). Future studies should examine the relationship between self-determined friendship motivation and aggression in situations manipulated to prompt aggressive responses.

There are some limitations to this study. First, the quality of friendships has not been measured. From previous studies, it was assumed that the good-quality relationships with friends mediated the relationship between aggression and self-esteem (Leary \& Baumeister, 2000). If so, aggression (especially, hostility and anger in this study) would predict poor relationships with friends, which, in turn, would be associated with lower levels of self-esteem. Future studies should examine the quality of friendships as well. Second, all the variables were measured simultaneously. The model examined in this study assumed the causal order that self-determined friendship motivation affects aggression, which, in turn, affects self-esteem. The simultaneous measurement, however, makes it difficult to interpret the findings in terms of causality. For example, it may be that people with lower levels of self-esteem display more hostility and anger. To verify the causal relationships among self-determined friendship motivation, aggression, and self-esteem, a longitudinal measurement is required.

\section{REFERENCES}

Ando, A., Soga, S., Yamasaki, K., Shimai, S., Shimada, H., Utsuki, N., Oashi, O., \& Sakai, A. (1999). Development of the Japanese version of the Buss-Perry Aggression Questionnaire (BAQ). Japanese Jour- 
nal of Psychology, 70, 384-392. doi:10.4992/jjpsy.70.384

Barefoot, J. C., Dahlstrom, W. G., \& Williams, R. B. Jr. (1983). Hostility, CHD incidence, and total mortality: A 25 -year follow-up study of 255 physicians. Psychosomatic Medicine, 45, 59-63.

Baumeister, R. F., Smart, L., \& Boden, J. M. (1996). Relation of threatened egotism to violence and aggression: The dark side of high self-esteem. Psychological Review, 103, 5-33. doi:10.1037/0033-295X.103.1.5

Boiché, J. C. S., \& Sarrazin, P. G. (2007). Self-determination of contextual motivation, inter-context dynamics and adolescents' patterns of sport participation over time. Psychology of Sport and Exercise, 8, 685-703. doi:10.1016/j.psychsport.2006.10.004

Buhrmester, D., Furman, W., Wittenberg, M. T., \& Reis, H. T. (1988). Five domains of interpersonal competence in peer relationships. Journal of Personality and Social Psychology, 55, 991-1008. doi:10.1037/0022-3514.55.6.991

Buss, A. H., \& Perry, M. (1992). The aggression questionnaire. Journal of Personality and Social Psychology, 63, 452-459. doi:10.1037/0022-3514.63.3.452

Byrne, B. M. (2001). Structural equation modeling with AMOS: Basic concepts, applications and programming. Mahwah, NJ: Erlbaum.

Deci, E. L., \& Ryan, R. M. (2000). The "what" and "why" of goal pursuits: Human needs and the self-determination of behavior. Psychological Inquiry, 11, 227-268. doi:10.1207/S15327965PLI1104 01

Deci, E. L., Ryan, R. M., Gagné, M., Leone, D. R., Usunov, J., \& Kornazheva, B. P. (2001). Need satisfaction, motivation, and well-being in the work organizations of a former Eastern Bloc country: A crosscultural study of self-determination. Personality and Social Psychology Bulletin, 27, 930-942. doi:10.1177/0146167201278002

Elliot, A. J., Gable, S. L., \& Mapes, R. R. (2006). Approach and avoidance motivation in the social domain. Personality and Social Psychology Bulletin, 32, 378-391. doi: $10.1177 / 0146167205282153$

Felston, G. \& Hill, V. (1999). Aggression Questionnaire hostility scale predicts anger in response to mistreatment. Behaviour Research and Therapy, 37, 87-97. doi:10.1016/S0005-7967(98)00104-1

Gerevich, J., Bácskai, E., \& Czobor, P. (2007). The generalizability of the Buss-Perry Aggression Questionnaire. International Journal of Methods in Psychiatric Research, 16, 124-136. doi: $10.1002 / \mathrm{mpr} .221$

Grolnick, W. S., \& Ryan, R. M. (1987). Autonomy in children's learning: An experimental and individual difference investigation. Journal of Personality and Social Psychology, 52, 890-898. doi:10.1037/0022-3514.52.5.890

Harmon-Jones, E. (2003). Anger and the behavioral approach system. Personality and Individual Differences, 35, 995-1005. doi:10.1016/S0191-8869(02)00313-6

Harris, J. A. (1997). A further evaluation of the aggression questionnaire: Issues of validity and reliability. Behaviour Research Therapy, 35, 1047-1053. doi:10.1016/S0005-7967(97)00064-8

Hartup, W. W., \& Stevens, N. (1997). Friendships and adaptation in the life course. Psychological Bulletin, 121, 355-370. doi:10.1037/0033-2909.121.3.355

Hawley, P. H., Little, T. D., \& Pasupathi, M. (2002). Winning friends and influencing peers: Strategies of peer influence in late childhood. International Journal of Behavioral Development, 26, 466-474. doi:10.1080/01650250143000427

Jarvinen, D. W., \& Nicholls, J. G. (1996). Adolescents' social goals, beliefs about the causes of social success, and satisfaction in peer relations. Developmental Psychology, 32, 435-441. doi:10.1037/0012-1649.32.3.435

Knee, C. R., Lonsbary, C., Canevello, A., \& Patrick, H. (2005). Self-determination and conflict in romantic relationships. Journal of Personality and Social Psychology, 89, 997-1009. doi:10.1037/0022-3514.89.6.997

Leary, M. R., \& Baumeister, R. F. (2000). The nature and function of self-esteem: Sociometer theory. In M. P. Zanna (Ed.), Advances in experimental social psychology (Vol. 32, pp. 1-62). San Diego, CA:
Academic Press.

Leary, M. R., Tambor, E. S., Terdal, S. K., \& Downs, D. L. (1995). Self-esteem as an interpersonal monitor: The sociometer hypothesis. Journal of Personality and Social Psychology, 68, 518-530. doi:10.1037/0022-3514.68.3.518

Levesque, C., Zuehlke, A. N., Stanek, L. R., \& Ryan, R. M. (2004). Autonomy and competence in German and American university students: A comparative study based on self-determination theory. Journal of Educational Psychology, 96, 68-84. doi: $10.1037 / 0022-0663.96 .1 .68$

Losier, G., \& Vallerand, R. J. (1994). The temporal relationship between perceived competence and self-determined motivation. The Journal of Social Psychology, 134, 793-801. doi: $10.1080 / 00224545.1994 .9923014$

Lucas, R. E., \& Dyrenforth, R. S. (2006). Does the existence of social relationships matter for subjective well-being? In K. D. Vohs, \& E. J. Finkel (Eds.), Self and relationships: Connecting intrapersonal and interpersonal processes (pp. 254-273). New York, NY: Guilford Press.

Matsushima, R., \& Shiomi, K. (2003). Developing a scale of self-efficacy in personal relationships for adolescents. Psychological Reports, 92, 177-184.

Miller, T. Q., Smith, T. W., Turner, C. W., Guijarro, M. L., \& Hallet, A. J. (1996). A meta-analytic review of research on hostility and physical health. Psychological Bulletin, 119, 322-348. doi:10.1037/0033-2909.119.2.322

O'Connor, D. B., Archer, J., \& Wu, F. W. C. (2001). Measuring aggression: Self-reports, partner reports, and responses to provoking scenarios. Aggressive Behavior, 27, 79-101. doi:10.1002/ab.2

Okada, R. (2005). Development of a friendship motivation scale in the framework of the self-determination theory. Japanese Journal of Personality, 14, 101-112. doi:10.2132/personality.14.101

Okada, R. (2006). Effects of autonomous friendship motivation on self-disclosure and adjustment. Japanese Journal of Personality, 15, 52-54. doi:10.2132/personality. 15.52

Okada, R. (2007). Motivational analysis of academic help-seeking: Self-determination in adolescents' friendship. Psychological Reports, 100, 1000-1012. doi:10.2466/pr0.100.3.1000-1012

Patrick, H., Ryan, A. M., \& Kaplan, A. (2007). Early adolescents' perceptions of the classroom social environment, motivational beliefs, and engagement. Journal of Educational Psychology, 99, 83-98. doi:10.1037/0022-0663.99.1.83

Richard, J. F., \& Schneider, B. H. (2005). Assessing friendship motivation during preadolescence and early adolescence. Journal of Early Adolescence, 25, 367-385. doi:10.1177/0272431605276930

Ryan, A. M., \& Shim, S. S. (2006). Social achievement goals: The nature and consequences of different orientations toward social competence. Personality and Social Psychology Bulletin, 32, 1246-1263. doi: $10.1177 / 0146167206289345$

Sénecal, C., Julien, E., \& Guay, F. (2003). Role conflict and academic procrastination: A self-determination perspective. European Journal of Social Psychology, 33, 135-145. doi:10.1002/ejsp.144

Shahar, G., Henrich, C. C., Blatt, S. J., \& Ryan, R. (2003). Interpersonal relatedness, self-definition, and their motivational orientation during adolescence: A theoretical and empirical integration. Developmental Psychology, 39, 470-483. doi:10.1037/0012-1649.39.3.470

Soenens, B., \& Vansteenkiste, M. (2005). Antecedents and outcomes of self-determination in 3 life domains: The role of parents' and teachers' autonomy support. Journal of Youth and Adolescence, 34, 589604. doi:10.1007/s10964-005-8948-y

Twenge, J. M. (2006). When does social rejection lead to aggression? The influences of situations, narcissism, emotion, and replenishing connections. In K. D. Williams, J. P. Forgas, \& W. von Hippel (Eds.), The social outcast: Ostracism, social exclusion, rejection, and bullying (pp. 201-212). New York, NY: Psychology Press.

Yamamoto, M., Matsui, Y., \& Yamanari, Y. (1982). The structure of perceived aspects of the self. Japanese Journal of Educational Psychology, 30, 64-68. 